\title{
MONITORING SUHU MENGGUNAKAN METODE KONSENSUS TERDISTRIBUSI RATA-RATA PADA JARINGAN SENSOR NIRKABEL UNTUK APLIKASI SISTEM RUMAH PINTAR
}

\author{
Yoedo Ageng Suryo $\mathbf{S}^{1)}$ \\ Raafi Yanuar Purnama Arifian ${ }^{2}$ \\ 1,2,) Jurusan Teknik Elektro, Fakultas Teknik, Universitas Muhammadiyah Gresik \\ 1) mryoedo@gmail.com, ${ }^{2}$ rafi.arifian1@gmail.com \\ Jl. Sumatra No 101, Gresik 61121, Jawa Timur, Indonesia
}

\begin{abstract}
ABSTRAK
Proses monitoring suhu pada ruangan yang luas, dibutuhkan banyak node sebagai penginderaan data yang dapat mewakili area tersebut. Penelitian ini menggunakan Metode Konsensus Terdistribusi Rata-rata untuk mendapatkan perwakilan data dari suatu jaringan sensor nirkabel suatu area. Setelah dilakukan pengukuran dan perhitungan link budget diperoleh kekuatan sinyal terima berdasarkan pengukuran pada saat jarak terjauh yaitu $200 \mathrm{~m}$ sebesar $-98 \mathrm{dBm}$. Sedangkan berdasarkan perhitungan dengan daya pancar $10 \mathrm{dBm}$ dengan jarak yang sama diperoleh kekuatan sinyal terima sebesar -67,17 dBm. Pengujian efek Doppler memperlihatkan semakin kecil SF maka semakin tidak rentan terkena efek Doppler. Hasil simulasi metode konsensus terdistribusi rata-rata memperlihatkan semakin banyak slot yang terisi oleh data hasil konsensus maka semakin cepat dan mudah tercapai konvergensi dalam hal ini hasil monitoring mempresentasikan keadaan yang sebenarnya.
\end{abstract}

Kata kunci: internet, things, konvergen, sensor, nirkabel

\section{PENDAhuluan}

\subsection{Latar Belakang}

Internet of Things (IoT) mengacu pada sejumlah jaringan IP dan beberapa perangkat seperti sensor dan actuator yang dilengkapi dengan perangkat antarmuka telekomunikasi juga unit pemrosesan dan penyimpanan data. [1] Proses komunikasi ini harus terintegrasi untuk saling menghubungkan antar objek. Banyak model sistem komunikasi yang digunakan dalam implemtasi IoT seperti pada [2] yang membahas tentang model evaluasi jangkauan dan redaman kanal untuk teknologi LoRa pada yang baik jaringan area yang luas dengan konsumsi daya rendah. Sedangkan dalam [3] dibahas model sistem komunikasi menggunakan Zigbee untuk penentuan posisi suatu node. Penelitian ini menggunakan metode consensus rata-rata pada jaringan sensor nirkabel untuk mendapatkan perwakilan data penginderaan pada area yang luas.

\subsection{Rumusan Masalah}

Mensimulasikan dan menerapkan jaringan sensor nirkabel pada area untuk implementasi metode konsensus rata-rata.

\subsection{Tujuan Penelitan}

Merancang aplikasi metode konsensus terdistribusi rata-rata pada jaringan sensor nirkabel untuk monitoring suhu.

\section{I.I Tinjauan Pustaka}

\subsection{Arsitektur Jaringan Sensor Nirkabel}

Sejumlah node sensor yang bertempat di suatu area difungsikan untuk pengumpulan data secara nirkabel dan mengirim ke bagian pusat untuk proses pengolahan data. Node ini 
terdiri dari sub sistem penginderaan, pemrosesan dan komunikasi. Dimana sub sistem pemrosesan adalah perangkat utama dari sebuah node dan pemilihan prosesor didasarkan pada keefisienan dan fleksibilitas dalam hal ini energi unjuk kerja. Proses ini membutuhkan sistem nirkabel antara komponen pengindera dan pusat data yang mempunyai kemampuan untuk pemroses, komunikasi dan penyimpanan. Komunikasi antar jaringan sensor menggunakan sinyal radio yang meliputi penyebaran data untuk pemrosesan jarak jauh, penggambaran, analisa dan sistem penyimpanan.

\subsection{Pemodelan Sistem Komunikasi Nirkabel}

Penelitian ini menggunakan modulasi sinyal berdasarkan chrip spread spectrum yang ditransmisikan dari perangkat akhir [5].

$s(t)=\left\{\begin{array}{c}A(t) \cos \left[\left(\omega_{0}+\omega_{D}\right) t+\frac{\mu t^{2}}{2}\right] \cdots . . \\ -\frac{T}{2}<t<\frac{T}{2}\end{array}\right\}$

A : amplitude sinyal

$\omega_{0} \quad$ : frekuensi anguler sinyal carier

$\omega_{D} \quad$ : perpindahan frekuensi anguler

$t \quad$ : waktu

$\mu \quad$ : laju sinyal chirp

$T \quad$ : durasi sinyal chirp

Sinyal css biasa dikenal dengan upchrip ketika frekuensi meningkat secara linear dan down-chirp ketika frekuensi menurun.

\subsection{Perhitungan Link Budget}

Merupakan perhitungan pelemahan sinyal terhadap jarak [6].

$P_{L}=|R S S I|+P_{t x}+G_{t x}+G_{r x}$

$P_{L} \quad$ : Redaman

$R S S I$ : daya terima

$P_{t x} \quad$ : daya pancar

$G_{t x} \quad$ : penguat pemancar

$G_{r x} \quad$ : penguat penerima

Dengan mengetahui nilai komponen redaman dari log-distance maka nilai redaman dapat diperoleh [7].
$P_{L}=10 \times n \times \log _{10}(d)+P_{L o}$

$\mathrm{n} \quad$ : komponen redaman

d : jarak dua node

$P_{L 0} \quad$ : redaman yang terukur pada jarak pertama

\subsection{Unjuk Kerja Sistem}

Perhitungan BER berdasarkan proses probabilitas dari banyaknya data yang diterima terhadap yang dikirimkan.

$B E R=\frac{\text { data yang diterima }}{\text { total data terkirim }} \times 100 \%$

\subsection{Metode Konsensus}

Merupakan metode pengembangan dengan sistem multi-agen dimana setiap nilai yang diupdate oleh tiap node merupakan kombinasi pembobotan linear dari nilai yang diperoleh sendiri dan nilai yang diterima dari node tetangga [14]. Tiap node memelihara sebuah table yang berisi nilai awal dari semua node yang ada. Setiap tahap node-node saling bertukar informasi dari tabelnya sendiri ke table tetangga. Setelah jumlah dari setiap tahap sama dengan ukuran jaringan, setiap node mengetahui semua nilai awal dari semua node, maka nilai rata-rata dapat dihitung [15].

$x_{i}(t+1)=W_{i i} x_{i}(t)+\sum_{j=0}^{N} W_{i j} x_{j}$

$x_{i} \quad$ : data sensor ke $\mathrm{i}$

$W_{i i} \quad$ : nilai pembobot sensor ke i

$W_{i j} \quad$ : nilai pembobot sensor tetangga

$x_{j} \quad$ : data sensor tetangga

\section{Dasar Teori}

\subsection{Pemodelan Algoritma}

Untuk mendapatkan data yang sesuai dengan algoritma consensus terdistribusi rata-rata perlu adanya pembobot [16] dimana jika pembobotan adalah suatu nilai variable antara 0.1 hingga 0.9 maka nilai ini bias digantikan dengan prosentase antara $10 \%$ hingga $90 \%$. 
Tabel 1 Pembobotan Node

\begin{tabular}{|c|c|c|c|}
\hline Pembobot & Prosentase & $\begin{array}{c}\text { Data } \\
\text { Node } \\
\text { Tentangga }\end{array}$ & $\begin{array}{c}\text { Data } \\
\text { Node } \\
\text { Sendiri }\end{array}$ \\
\hline 0,1 & $10 \%$ & 2 & 18 \\
\hline 0,2 & $20 \%$ & 4 & 16 \\
\hline 0,3 & $30 \%$ & 6 & 14 \\
\hline 0,4 & $40 \%$ & 8 & 12 \\
\hline 0,5 & $50 \%$ & 10 & 10 \\
\hline 0,6 & $60 \%$ & 12 & 8 \\
\hline 0,7 & $70 \%$ & 14 & 6 \\
\hline 0,8 & $80 \%$ & 16 & 4 \\
\hline 0,9 & $09 \%$ & 18 & 2 \\
\hline
\end{tabular}

Pada gambar 1 dimulai dengan inisialisasi data masing-masing node dan node tetangga. Kemudian dilanjutkan dengan memasukkan data hasil pengeinderaan sendiri maupun tetangga yang dilanjut dengan analisis estimasi.

Untuk pengiriman data antar node dibuatkan penjadwalan dan jeda pengulangan untuk melakukan penginderaan. Hal ini dilakukan agar data yang diterima oleh masing-masing node dapat dideteksi asal sumber data.

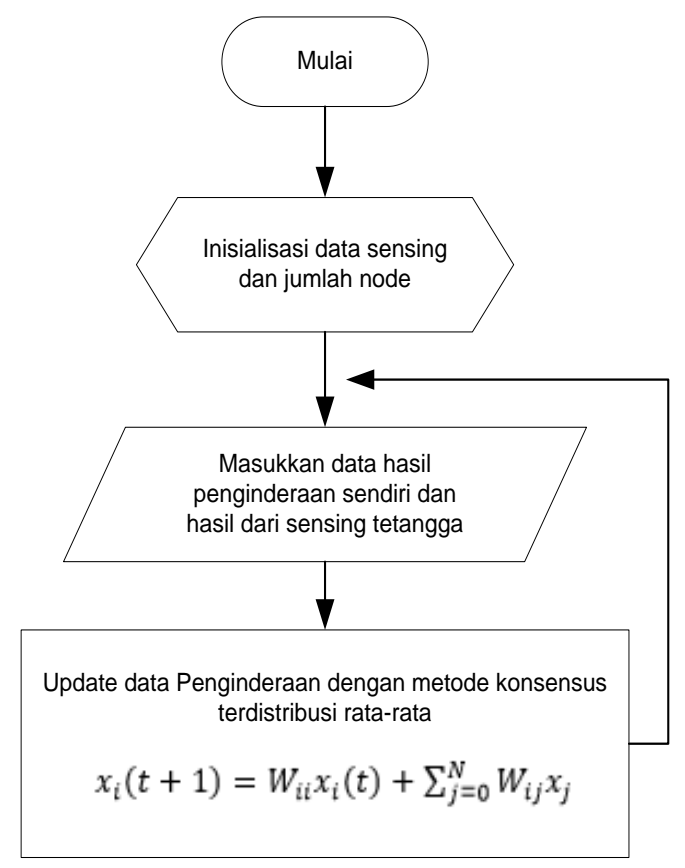

Gambar 1. Algoritma Konsensus Terdistribusi Rata-rata

\subsection{Pengujian Link Budget}

Berdasarkan persamaan 2, 3 dan 4 maka perhitungan nilai RSSI dibandingkan dengan data yang diperoleh dari hasil pengukuran nilai RSSI antara dua node yang saling berkomunikasi. Data perhitungan menggunakan tiga daya pancar sebesar $0 \mathrm{~dB}$, $5 \mathrm{~dB}$ dan $10 \mathrm{~dB}$. Penelitian ini dibuat program pengiriman data suhu dari dua node yang berbeda yang dilengkapi dengan data RSSI di masing-masing node sehingga nilai ini dibandingkan secara teori.

\subsection{Pengujian Kesalahan Pengiriman Data}

Dilakukan dengan pengiriman sinyal data jarak tertentu sebanyak 100 kali pengiriman data. Selanjutnya akan terdapat prosentase kesalahan data sebagai unjuk kerja sistem.

\subsection{Pengujian Metode Konsensus}

Berdasarkan algoritma seperti pada gambar 1, dilakukan dengan mengatur pembobotan pada waktu tertentu untuk mendapatkan nilai yang konvergen.

\section{Hasil dan Diskusi}

\subsection{Pengujian Link Budget}

Pengujian pertama dilakukan dengan pengukuran kekuatan sinyal disertai beberapa jarak yang berbeda. Hasil pengukuran kekuatan sinyal menghasilkan data seperti pada Tabel 2.

Tabel 2 Pengukuran dan Perhitungan Link Budget

\begin{tabular}{|c|c|c|c|c|c|}
\hline No & $\begin{array}{c}\text { Jarak } \\
(\mathrm{m})\end{array}$ & $\begin{array}{c}\text { Pengukuran } \\
(\mathrm{dB})\end{array}$ & \multicolumn{3}{|c|}{ Perhitungan $(\mathrm{dB})$} \\
\cline { 4 - 6 } & & & $\begin{array}{c}\mathrm{Pt}= \\
0 \mathrm{~dB}\end{array}$ & $\begin{array}{c}\mathrm{Pt}=5 \\
\mathrm{~dB}\end{array}$ & $\begin{array}{c}\mathrm{Pt}= \\
10 \\
\mathrm{~dB}\end{array}$ \\
\hline 1 & 1 & -30 & 25,14 & 30,14 & 35,14 \\
\hline 2 & 3 & -57 & 3,7 & 8,7 & 13,7 \\
\hline 3 & 5 & -64 & $-6,24$ & $-1,24$ & 3,76 \\
\hline 4 & 50 & -83 & - & - & - \\
& & & 51,14 & 46,14 & 41,14 \\
\hline 5 & 100 & -92 & - & - & - \\
& & & 64,66 & 59,66 & 54,66 \\
\hline 6 & 200 & -98 & - & - & - \\
& & & 78,17 & 73,17 & 68,17 \\
\hline
\end{tabular}


Volume 15 Nomor 2 (2020) 16-22

E-Link P-ISSN 1858-2109 E-ISSN 2656-5676

Jurnal Teknik Elektro dan Informatika

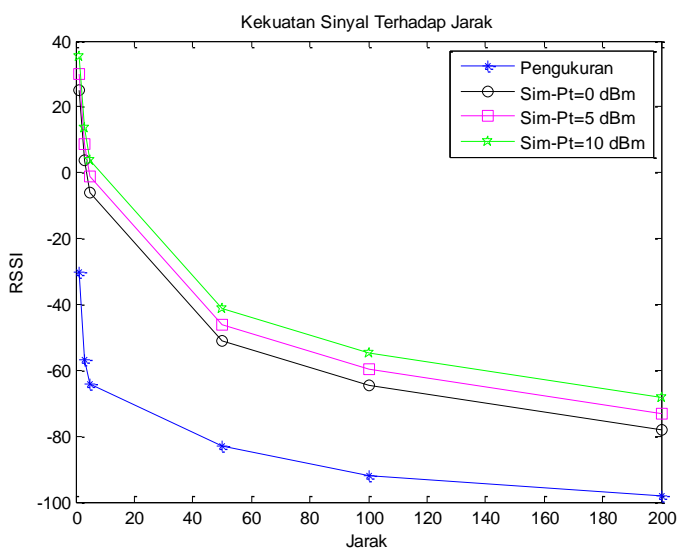

Gambar 2 Pengukuran dan Perhitungan Kekuatan Sinyal

Berdasarkan pengukuran kekuatan sinyal menurun seiring dengan meningkatnya jarak antara dua node yang berkomunikasi. Sinyal terjelek yang diterima oleh node berdasarkan pengukuran adalah $-98 \mathrm{dBm}$ ketika jarak mencapai $200 \mathrm{~m}$ seperti ditunjukan pada grafik warna biru. Hasil simulasi memperlihatkan semakin tinggi daya pancar maka semakin baik kekuatan sinyal terima. Kekuatan sinyal terima terbaik dicapai ketika daya pancar yang digunakan adalah $10 \mathrm{dBm}$ yaitu $-68,17 \mathrm{dBm}$ pada jarak $200 \mathrm{~m}$.

\subsection{Pengujian Kesalahan Pengiriman Data}

Pengujian kesalahan data dilakukan dengan percobaan pengiriman data antara dua node yang saling berkomunikasi sebanyak 35 variasi jarak perbedaan jarak sepanjang $1 \mathrm{~m}$. Berdasarkan perhitungan diperoleh kesalahan pengiriman data seperti pada gambar 3 .

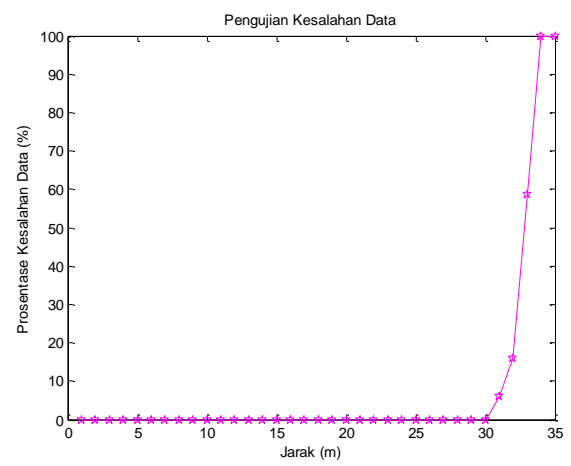

Gambar 3 Pengujian Kesalahan Pengiriman Data
Semakin jauh jarak komunikasi maka semakin besar prosentase kesalahan pengirimana data. Terlihat dari jarak $31 \mathrm{~m}$ terjadi kesalahan dengan prosentase rata-rata sebesar 6\% dan sejak jarak $34 \mathrm{~m}$ maka tidak ada data yang diterima sehingga prosentasi rata-rata kesalahan pengiriman data sebesar $100 \%$.

\subsection{Pengujian Efek Doppler}

Efek Doppler merupakan salah satu gangguan pada sistem komunikasi nirkabel dimana hal ini akan terjadi jika waktu simbol melebihi waktu koheren. Perhitungan ini diatur nilai Spreading Factor dan Bandwidth yaitu $\mathrm{BW}=125 \mathrm{kbps}$ dengan $\mathrm{SF}=12, \mathrm{BW}=125$ $\mathrm{kHz}$ dengan $\mathrm{SF}=11, \mathrm{BW}=125 \mathrm{kHz}$ dengan $\mathrm{SF}=10$ dan $\mathrm{BW}=250 \mathrm{kHz}$ dengan $\mathrm{SF}=7$. Hasil perhitungan ditunjukkan pada Gambar 4.

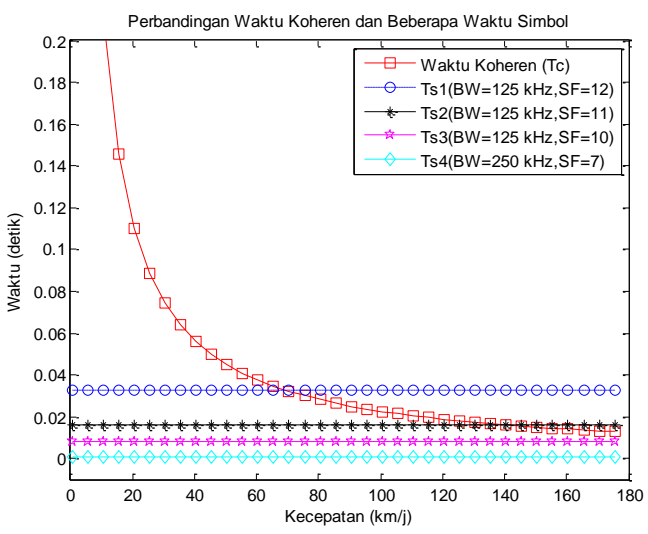

Gambar 4 Pengukuran dan Perhitungan Kekuatan Sinyal

Berdasarkan gambar 4 terlihat bahwa waktu koheren selalu berada diatas waktu symbol yang menunjukkan parameter efek Doppler tidak akan pernah terjadi.

\subsection{Pengujian Metode Konsensus Rata-rata}

Pengujian metode consensus rata-rata dilakukan dengan mensimulasikan algoritma dilakukan dengan mengambil nilai data suhu yang berbeda untuk tiap sensor yaitu Node1 $=28, \quad$ Node2 $=29, \quad$ Node $3=30$ dan Node4=31 maka diperoleh grafik hasil 
Volume 15 Nomor 2 (2020) 16-22

E-Link P-ISSN 1858-2109 E-ISSN 2656-5676

Jurnal Teknik Elektro dan Informatika

simulasi untuk pembobot 0,1 sampai 0,9 seperti pada kumpulan gambar berikut.

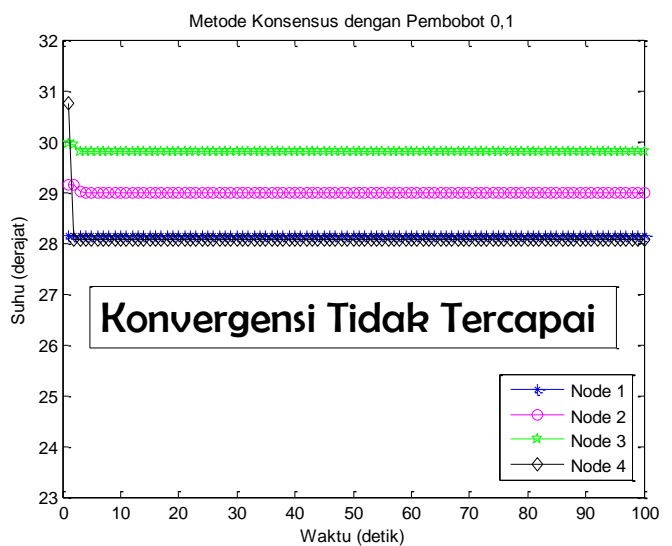

(a) Pembobot 0,1 yaitu 18 slot untuk Sensing dan 2 slot dari Node Tetangga

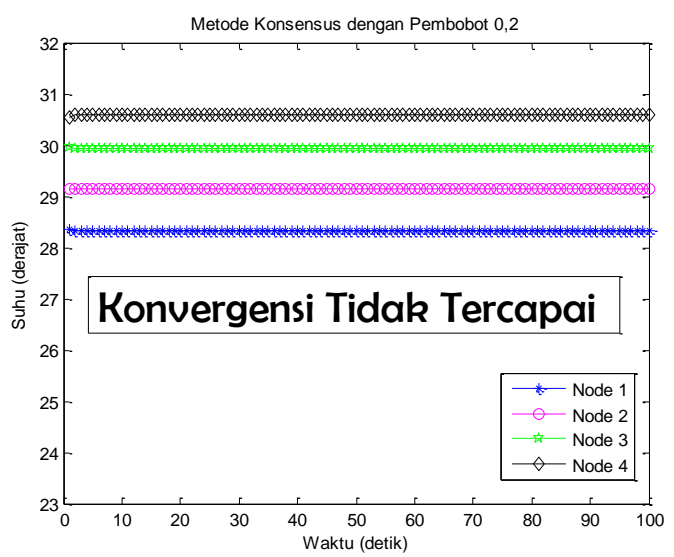

(b) Pembobot 0,2 yaitu 16 slot untuk Sensing dan 4 slot dari Node Tetangga

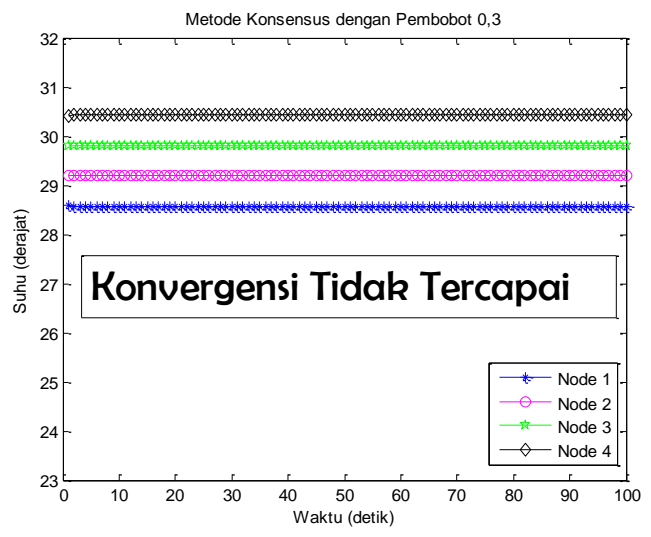

Pembobot 0,3 yaitu 14 slot untuk Sensing dan 6 slot dari Node Tetangga

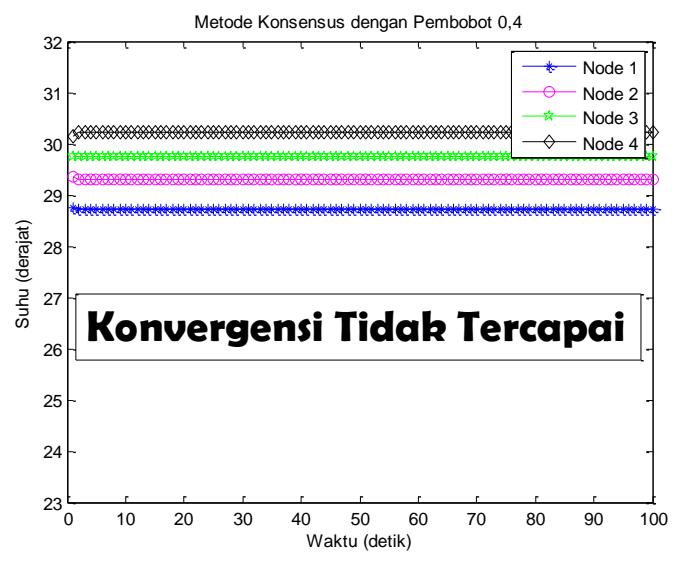

(d) Pembobot 0,4 yaitu 12 slot untuk Sensing dan 8 slot dari Node Tetangga

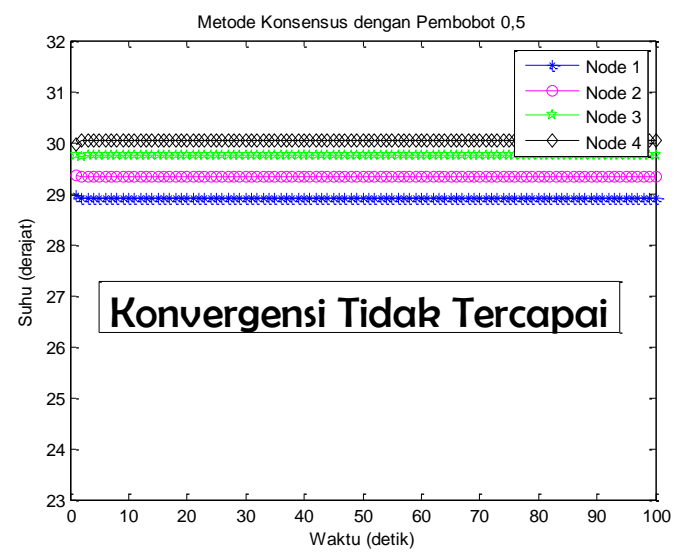

(e) Pembobot 0,5 yaitu 10 slot untuk Sensing dan 10 slot dari Node tetangga

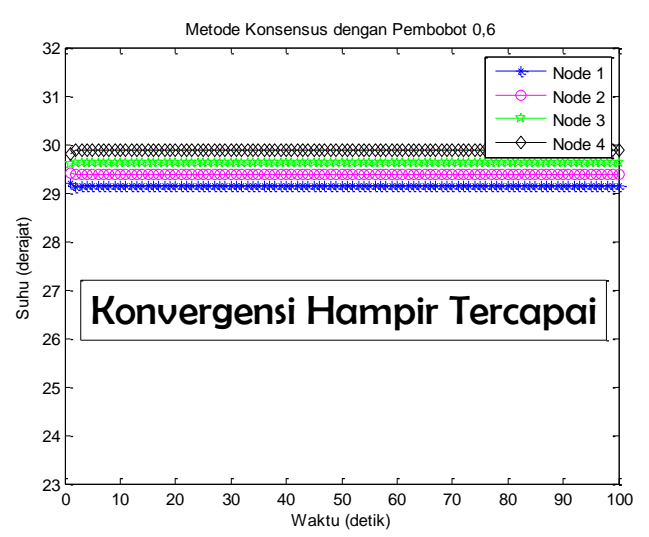

(f) Pembobot 0,6 yaitu 8 slot untuk Sensing dan 12 slot dari Node Tetangga 
Volume 15 Nomor 2 (2020) 16-22

E-Link P-ISSN 1858-2109 E-ISSN 2656-5676

Jurnal Teknik Elektro dan Informatika

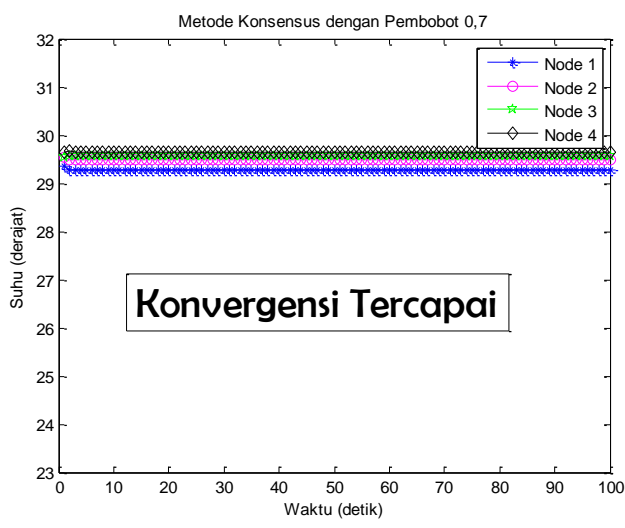

(g) Pembobot 0,7 yaitu 6 slot untuk Sensing dan 14 slot dari Node Tetangga

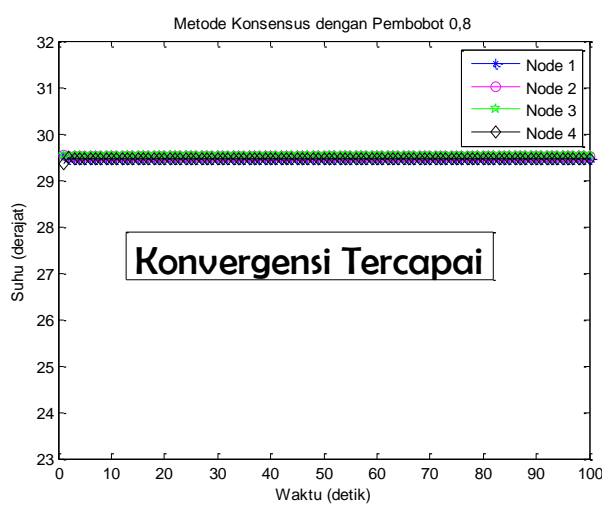

(h) Pembobot 0,8 yaitu 4 slot untuk Sensing dan 16 slot dari Node Tentangga

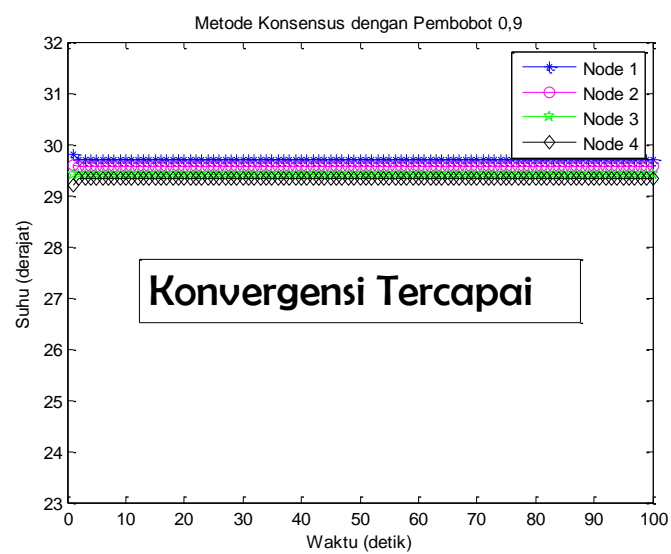

(i) Pembobot 0,9 yaitu 2 slot untuk sensing 18 slot dari Node tetangga

Berdasarkan kumpulan gambar di atas, pembobot 0,1 sampai 0,5 , konvergensi tidak tercapai karena data dalam slot didominasi oleh data sensing bukan data dari hasil konsensus. Sedangkan pembobot 0,7 sampai 0,9 konvergensi tercapai dan data dalam slot keseluruhan adalah data hasil konsensus diantara keempat node yang berkomunikasi. Waktu konvergensi tercepat sebesar 1 detik dengan suhu hasil konsensus adalah $29,5^{\circ} \mathrm{C}$.

\section{Kesimpulan}

4.1 Kesimpulan

a. Pengukuran berdasarkan percobaan menghasilkan kekuatan sinyal terima terjelek adalah $-98 \mathrm{dBm}$ pada jarak 200 m. sedangkan berdasarkan perhitungan diperoleh -68.17 pada jarak $200 \mathrm{~m}$ dengan daya pancar $10 \mathrm{dBm}$.

b. Kesalahan pengiriman data juga dilakukan pengujian sebanyak 35 variasi jarak dengan perbedaan jarak maksimum untuk pengiriman data adalah $34 \mathrm{~m}$ dimana prosentasi kesalahan terjadi hingga 100\%.

c. Pengujian efek Doppler menghasilkan efek Doppler terjadi ketika SF 12 dan bandwidth $125 \mathrm{kHz}$ pada saat kecepatan melebihi 70.5 $\mathrm{km} / \mathrm{jam}$. Efek Doppler tidak terjadi pada waktu SF 7 dengan bandwidth $250 \mathrm{kHz}$ dan $\mathrm{SF} 10$ dengan bandwidth $250 \mathrm{kHz}$ karena waktu symbol tidak pernah melebihi waktu koheren.

d. Pengujian metode consensus ratarata menghasilkan waktu konvergensi saat pembobot sebesar 0.7 dimana komposisi slot tiap node adalah 6 slot berisi hasil penginderaan dan 14 sl data consensus dari node tetangga.

\subsection{Saran}

a. Perlu adanya penambahan node untuk mendapatkan hasil konvergensi seperti yang lebih real.

b. Perlunya ditambahkan penjelasan protocol komunikasi lainnya seperti MQTT, REST API. 


\section{DAFTAR PUSTAKA}

[1] Juha petajajarvi, konstantin mikjaylov, antti roivainen, tuomo hanninen, and marko pettissalo, "on the coverage of lpwans: range evaluation and channel attenuation model for lora technology," in 2015 14th international conference on its telecommunication (itst), copenhagen, 2015, pp. 55-59.

[2] Aries pratiarso et al., "skema lokalisasi posisi node terdistribusi pada lingkungan free space path loss," jurnal nasional teknik elektro dan teknologi informasi, vol. 6, no. 3, pp. 352-358, agustus 2017.

[3] Waltenegus dargie and christian poellabauer, fundamentals of wireless sensor networks theory and practise, 1st ed., xuemin shen and yi pan, eds. Southern gate, united kingdom: john wiley \& son ltd., 2010.

[4] Achmad fauzi rachmani and fitri yuli zulkifli, "trial and evaluation of lora performance for smart sistem multi-client model," in international seminar intelligent technolgy on its application, denpasar, bali, august 2018, pp. 33-38.

[5] Muhammad nurkholis, "perancangan dan pembuatan sistem monitoring suhu dan kelembaban ruangan dengan kamera berbasis rasberry pi b+," teknik komputer dan informatika, 2015.

[6] Lin xiao and stephen boyd, "fast linear iterations for distributed averaging," elseiver, vol. Sistems \& control letters, no. 53, pp. 65-78, 2004.

[7] Dwi edi setyawan, wirawan, and istas pratomo, "algoritma konsensus rata-rata terdistribusi pada wireless sensor networks berbasis link infrared," surabaya, 2016. 